\title{
The Eleatic and the Indispensabilist
}

\author{
Russell Marcus
}

Received: 01/07/2014

Final Version: 30/04/2015

BIBLID 0495-4548(2015)30:3p.415-429

DOI: $10.1387 /$ theoria. 12009

ABSTRACT: The debate over whether we should believe that mathematical objects exist quickly leads to the question of how to determine what we should believe to exist. Indispensabilists claim that we should believe in the existence of mathematical objects because of their ineliminable roles in scientific theory. Eleatics argue that only objects with causal properties exist. Mark Colyvan's recent defenses of Quine's indispensability argument present an intriguing attempt to provide reasons to favor the indispensabilist's criterion against some contemporary eleatics. I show that Colyvan's argument is not decisive against the eleatic and then sketch a way to capture some of the important intuitions behind both views.

Keywords: indispensability argument, Eleatic principle, autonomy platonism, Mark Colyvan.

RESUMEN: El debate sobre si deberíamos creer en la existencia de los objetos matemáticos conduce rápidamente a la cuestión de cómo determinar lo que deberíamos creer que existe. Los indispensabilistas declaran que deberíamos creer en la existencia de los objetos matemáticos por sus funciones ineliminables en la teoría científica. Los eleáticos argumentan que sólo existen los objetos que tienen propiedades causales. La defensa reciente de Mark Colyvan del argumento de la indispensabilidad de Quine representa un interesante intento de proporcionar razones a favor del criterio indispensabilista, en contra de algunos eleáticos contemporáneos. Mostraré que el argumento de Colyvan en contra de los eleáticos no es decisivo y esbozaré a continuación una manera de capturar algunas de las importantes intuiciones que se encuentran tras ambos puntos de vista.

Palabras clave: argumento indispensabilista, principio eleático, platonismo de la autonomía, Mark Colyvan.

\section{Introduction}

The debate over mathematical realism is old and open. ${ }^{1}$ W.V. Quine argued that we should believe in the existence of mathematical objects because of their indispensable uses in scientific theory. In contrast, philosophers with various motivations have argued for an eleatic principle which states, roughly, that only causally-active entities exist. The eleatic principle is sometimes invoked by its proponents to deny that we should believe in the existence of mathematical objects. So the debate over whether we should believe that mathematical objects exist can quickly lead to the question of how we should determine what to believe exists.

1 Mathematical realism, or platonism, is sometimes taken as the claim that some mathematical propositions are non-vacuously true, often called sentence or truth-value realism, and sometimes as the claim that some mathematical objects exist, often called object realism. Object realism is the same as sentence realism on the assumption of a standard semantics for mathematical sentences (i.e. one for which some mathematical sentences are non-vacuously true if and only if some mathematical objects exist). I'll work here with object realism. 
One danger of such a debate is that mathematical platonists, those who believe in the existence of mathematical objects, tend to prefer criteria which allow for the existence of mathematical objects while mathematical nominalists, those who deny the existence of mathematical objects, tend to favor restrictive criteria which eliminate the possibility of justifying beliefs in mathematical objects. One challenge in adjudicating between platonists and nominalists is to formulate criteria which do not beg the question.

Mark Colyvan defends Quine's indispensability argument and its criterion for determining our ontological commitments against contemporary eleatics. One thread of Colyvan's argument is promising precisely because it may be seen as independent of the debate over mathematical objects. Colyvan provides examples which could show that the eleatic principle is unacceptable even when applied to the non-mathematical portions of scientific theory.

In this paper, I first introduce the indispensabilist and eleatic positions, framing the debate so that it avoids being question-begging. Then I show that Colyvan's argument is not decisive against the eleatic. While the form of Colyvan's argument is correct and could in principle be used to show the falsity of the eleatic principle, the examples themselves are unsuccessful. Parallel considerations from the eleatic also fail to decide the matter, as does close examination of the indispensabilist's main argument against the eleatic, the doubletalk criticism. In the end, I sketch a platonist view of mathematics which, while not entailed by the central arguments of this paper, captures some of the advantages of each side, allowing us to maintain both the eleatic's claim that causal efficacy is central to our beliefs about how to understand the ontology of scientific theory and the indispensabilist's claim that some mathematical propositions are true.

\section{Quine's Argument}

Quine's indispensability argument QI proceeds as follows. ${ }^{2}$

QI1. We should believe only the theory which best accounts for our sense experience.

Q12. Our belief in a theory entails belief in all of its ontological commitments.

QI3. The ontological commitments of any theory are the objects over which that theory first-order quantifies.

QI4. The theory which best accounts for our sense experience first-order quantifies over mathematical objects.

QIC. We should believe that mathematical objects exist.

QI follows from Quine's general method for determining the ontological commitments of a theory. First, QI1-QI2, we choose a best theory. Then, QI3, we regiment that theory in a canonical language of first-order logic with identity. Last, QI4, we examine the domain of quantification of the theory to see which objects the theory requires in order to come out as true.

2 Quine nowhere presents a detailed indispensability argument, though he alludes to the argument throughout much of his work. See Quines 1939, 1948, 1951, 1955, 1958, 1960, 1978, and 1986. Quine and Goodman 1947 is a notable exception. QI is my reconstruction of Quine's argument. 
Quine's method applies to any theory. Theories which refer to trees, electrons, and numbers, and theories which refer to ghosts, caloric, and God, are equally amenable to Quine's procedure. The theory to which QI refers, and which purportedly yields mathematical objects, is designed to account for our sense experiences, including explaining, predicting, and representing them. In addition to its references to ordinary objects like trees, it refers to objects which we cannot, arguably, sense directly, like carbon atoms, and to some objects which we cannot sense at all, like sets. Some of the objects posited by my theory are constituents of ordinary objects, as carbon atoms constitute portions of trees. Other objects to which my theory refers (e.g. mathematical objects) are posited for more formal or technical reasons.

An often-overlooked virtue of Quine's argument, one worth keeping in mind, is that it obviates worries about access to mathematical objects. Our ontology is not determined by a reductionist account of our sense experience. We need not see mathematical objects to believe that they exist. Rather, our ontology is determined by the construction and interpretation of our theories.

There are a variety of possible negative responses to the Quinean argument. One possibility is to deny QI4. ${ }^{3}$ Another possibility is to deny Quine's method for determining the commitments of a theory.

\section{The Eleatic Principle}

Eleatics like David Armstrong and Jody Azzouni defend an alternative to Quine's method which has its roots in Plato's Sophist. ${ }^{4}$ The eleatic principle is notoriously difficult to articulate precisely. Armstrong emphasizes both causal activity and spatio-temporal location.

Against the suggestion that the world might contain...such things as possibilities, timeless propositions and "abstract" classes, I argued that these latter entities had no causal power; and that if they had no power there was no good reason to postulate them (Armstrong 1978b: 46).

The world is nothing but a single spatio-temporal system (Armstrong 1978a: 126).

In response, Oddie 1982 develops counter-examples to these and other expressions of the principle which illustrate the difficulty of formulating necessary and sufficient conditions. The difficulty is compounded by the eleatics' reliance on a concept, causation, which has puzzled philosophers since at least Hume's time and remains problematic. ${ }^{5}$

${ }^{3}$ Field 1980 spurred a range of projects denying QI4 by rewriting either mathematical or scientific theory to dispense with quantification over mathematical objects. Burgess and Rosen 1997 elegantly compiles many of these dispensabilist strategies. We can easily eliminate quantification over mathematical objects from first-order theories of standard science, using a variety of tricks which yield ugly, unwieldy theories. So, the Quinean must emphasize the 'best' in both QI1 and QI4.

4 "I am proposing as a mark to distinguish real things that they are nothing but power" (Sophist 247e, Cornford translation).

5 One live and salient question concerns the nature of objects related causally: Are they events, facts, features, states of affairs, or something else? The eleatic seeks to ground ontology in causation, but questions of ontology are difficult to answer unless we know what the causal relation relates. 
Despite difficulties formulating a precise eleatic principle, it is not unclear how the principle is intended as an alternative to QI regarding whether we should believe in mathematical objects. The eleatic claims that we should not believe in mathematical objects, even if they are included in our best theory, because they are not causally connected to the directly sensible, space-time world. They are mere heuristic devices. "If any entities outside the [spatio-temporal] system are postulated, but have no effect on the system, there is no compelling reason to postulate them" (Armstrong 1980: 154). ${ }^{6}$

For the purposes of this paper, I will focus on a paradigmatic formulation of the eleatic principle: 'Only those things which are causally active are real'. 7 The eleatic need not deny the indispensabilist's claims, at QI1 and QI2, that we should believe our best scientific theory and the posits that it makes. $S$ /he need not deny the holism which underlies those premises nor the naturalism which prompts the argument. Nor need the eleatic deny QI4, the claim that mathematics is ineliminable from our best theory. The central disagreement between the eleatic and the indispensabilist concerns how we read the posits from the theory, QI3. The eleatic claims that to be is to be causally active; our theory contains both real posits (e.g. trees, carbon atoms) and merely instrumental ones (e.g. the square root of two). The indispensabilist claims, "To be is to be the value of a variable" (Quine 1939: 50, and elsewhere), "To call a posit a posit is not to patronize it" (Quine 1960: 22), and that any distinction between real and instrumental posits in our best theory is arbitrary.

In contrast to the indispensabilist's latter criticism, the eleatic believes that $s /$ he has a principled way of distinguishing between real and instrumental elements of a theory: whatever the formulations of our theories require, mathematical objects are causally isolated from the rest of the world. Mark Balaguer calls the fact that we are unable to interact with mathematical objects the principle of causal isolation, or PCI. The commonsensical PCI is an eleatic principle and Balaguer wields it against the indispensability argument, noting the tension between QI and eleaticism. "The Quine-Putnam argument should be construed as an argument not for platonism or the truth of mathematics but, rather, for the falsity of PCI" (Balaguer 1998: 110).

The indispensabilist, embracing mathematical objects, accepts the existence of causally isolated entities. The eleatic, unwilling to accept anything causally isolated, rejects mathematical objects. The mathematical platonist may find QI convincing. The anti-platonist may be convinced by an eleatic principle. The indispensabilist's appeals to quantification over mathematical entities fail to convince the eleatic to abandon instrumentalism about them. The eleatic's appeals to the causal inefficacy of mathematical posits fail to appear relevant to the indispensabilist. Stalemate.

To decide between the two competing positions without begging the question of the existence of mathematical objects, we need reasons independent of mathematics to adopt either QI3 or an eleatic principle. In the next two sections I will show that recent attempts to provide such reasons, on both sides, do not succeed.

${ }^{6}$ Eleaticism may be the motivation for recent defenses of so-called easy-road (or weasel) nominalism, the claim that we can baldly deny mathematical commitments no matter how mathematics is used in theories we otherwise believe. See Melia 2000: 474; Leng 2002: 411; and Azzouni 2012.

7 Compare to Oddie 1982: 286; Field 1989: 68; Melia 2000: 474; and Azzouni 2004b: 150. 


\section{Colyvan's Defense of QI}

In defense of the indispensability argument, Colyvan argues that we are committed by physical theory to non-causal entities which play indispensable explanatory roles. If we admit non-causal, non-mathematical objects, then the eleatic principle fails independently of what we believe about mathematical objects. The door would be open to admit mathematical objects as well. And, Colyvan argues, there are good reasons to admit non-causal nonmathematical objects. Thus, according to Colyvan, the principled distinction which supports the eleatic's view is wrong.

Colyvan presents three examples. ${ }^{8}$ In the first example, Colyvan argues that the best explanation of light bending around large objects is geometric, rather than causal. "It's not that something causes the light to deviate from its usual path; it's simply that light travels along space-time geodesics and that the curvature of space-time is greater around massive objects" (Colyvan 2001: 47-8). Large masses covary with curvatures in spacetime, but it is not clear, on a causal picture, which causes which. Furthermore, according to the non-Minkowski vacuum solutions to the Einstein equation, there are empty, yet curved space-times. On the causal picture, these curvatures are uncaused, and thus unexplained.

Colyvan's second example concerns the existence of two antipodes in the Earth's atmosphere with exactly the same pressure and temperature at the same time. The causal explanation of this phenomenon, which refers to atmospheric conditions, suffices only to describe the existence of the antipodes, and does not explain why they inevitably exist. The existence of antipodes is guaranteed by a topological theorem. The proof of this theorem provides the remainder of the explanation and is non-causal.

Third, Colyvan asks us to consider the Fitzgerald-Lorentz contraction. A body in motion contracts, relative to an inertial reference frame, in the direction of motion. Minkowski's explanation of this contraction relies on equations in four dimensions, representing the space-time manifold. Colyvan calls this, "A purely geometric explanation of the contraction, featuring such non-causal entities as the Minkowski metric and other geometric properties of Minkowski space" (Colyvan 2001: 51).

To evaluate Colyvan's examples, recall that we are looking for non-causal entities other than mathematical objects which play an explanatory role. His argument is that since we need non-causal non-mathematical elements in our best theory, eleatic principles are shown false independently of the contentious mathematical case. If Colyvan's examples were to show only that mathematical elements of our best theory were indispensable, then using those examples to choose QI over an eleatic principle would be just like using a bare preference for mathematical realism to choose QI over an eleatic principle or a bare disdain for mathematical objects to choose an eleatic principle over QI.

Colyvan's first example, the geodesics, either begs the question or is insufficient. If we take the geodesics as pure mathematical objects, Colyvan begs the question by presenting a

8 These examples play a dual role in Colyvan's work in defending QI: against the eleatics who deny QI3 and against the dispensabilists like Hartry Field who deny QI4. My criticisms of Colyvan's examples in this paper apply only to their use against the eleatic and not to their use supporting QI4 against the indispensabilist. (Note that the three examples are present in Colyvan 2001, but only the second and third are present in Colyvan 1998 in which the problem is framed more aptly for present purposes.) 
geometric object as explanatory. If we take geodesics to be physical entities, then we should see them as properties of physical space-time, as opposed to objects of pure geometry. Ascribing causal properties to mathematical entities may be repugnant, but taking physical geometry to have causal relations to physical objects is not. We may naturally see masses as causing curvatures in physical space.

Colyvan rejects the causal interpretation. "[A]ny account that permits mass to cause the curvature of space-time is unintuitive to say the least" (Colyvan 2001: 48). The unintuitiveness, for Colyvan, may arise from thinking of space-time as abstract, or relationally. If we think of it substantivally, the causal explanation is not problematic. Indeed, any noncausal explanation of the curving geodesics near massive objects would make those curves seem entirely accidental. Without massive objects in or near their paths, light rays travel in straight lines.

The case of an empty, yet curved, space-time only reinforces the claim that we do not need a non-causal, non-mathematical explanation. The curvature of space-time is not an event which can be explained in terms of antecedent conditions, say. We can take it, with the substantivalist, to be a property of an object or collection of objects: space-time points or regions. Or we can take an empty yet curved manifold as a pure geometric object. In neither case do we need to posit non-causal, non-mathematical objects.

In Colyvan's second case, the antipodes, we must again make a pure/applied distinction regarding the topological theorem. The pure mathematical theorem does not guarantee that these antipodes have the same temperature and pressure. We need bridge principles which apply this theorem to the Earth and its weather patterns. Once we add these bridge principles, the proof which guarantees the antipodes may naturally be regarded as a causal explanation. For, the bridge principles will refer to causal structures within the Earth's atmosphere and it is these which explain the existence of the antipodes. This explanation will, as Colyvan notes, refer to non-causal entities such as continuous functions and spheres, but these are mathematical objects. We are looking for non-causal, yet non-mathematical, elements.

In the third example, the equations which explain contraction are supposed to make indispensable reference to non-causal entities: the Minkowski metric and other geometric properties of Minkowski space. Geometry, as in the bending-of-light example, can either be taken as a purely mathematical theory or as a description of the space-time manifold. In the latter case, we again may take space-time substantivally, in which case the geometric explanation of the contraction need not appeal to non-causal elements. ${ }^{9}$

In the former case, the Lorentz contraction is explained by a combination of mathematical objects (the equations which describe the transformations) and physical objects (the objects contracted). The equations apply to the physical world and thus explain the contraction of a physical body in motion when coupled with bridge principles which explain their applicability. ${ }^{10}$

It is a perennially interesting question why mathematical objects are applicable to physical theories, as in these cases. Colyvan's examples may well provide support for the

9 For a defense of space-time substantivalism, see Field 1989, Chapter 6.

${ }^{10}$ Melia writes similarly: "The Minkowski explanation is a geometric explanation of relativistic effects not a mathematical one" (Melia 2002: 76). 
indispensability argument, as examples supporting QI4. ${ }^{11}$ But, the indispensability of mathematics may be granted by eleatics without weakening their claim against the indispensabilists. The eleatic can claim that scientists use mathematics in order to express facts that are not representable without mathematics but that such representations are not supposed to be ontologically serious.

In none of his three cases has Colyvan shown that a non-causal entity, other than a mathematical object, plays an essential role in scientific explanation. The eleatic, ex bypothesi, need not show that mathematical entities can be removed from explanations in the physical world. Colyvan's examples fail to establish QI over eleatic principles.

\section{Eleaticism, Ideal Theories, and Double-Talk}

Let's turn to the eleatic. Azzouni defends eleaticism by arguing that accepting the indispensability argument would commit us to objects we do not really believe exist. He describes instances in which existential quantifications within science proper should be seen as merely instrumental. The users of scientific theories are not committed to centers of mass, quasi-particles, and mathematical objects. While the latter example is question-begging here, the first two examples are worth consideration.

Azzouni $1997 \mathrm{~b}$ considers a system of two masses connected by a spring, moving in a gravitational field. The separate motions of the masses are too complicated to calculate. But we can describe the system if we consider it in terms of its center of mass, which is not located on the springs, and its reduced mass. Our description of the system refers to its center of mass indispensably, according to Azzouni. Yet we know that the center of mass is not a real thing, but a merely instrumental posit. Thus Quine's method does not yield the proper results.

Quasi-particles, a second example from Azzouni, are posits used to replace one intractable many-body problem in condensed-matter physics with many one-body problems, using Fermi Liquid theory. Scientists introduce quasi-particles aware that a fictionalization is involved. "[I]t's not that physicists are failing to ask whether or not they're committed to the entities introduced in this way. They already take themselves not to be so committed. That's why, for example, such 'particles' are called quasi-particles" (Azzouni 1997b: 195).

Azzouni urges us to cleave ontological commitment from the existential quantifier while maintaining the quantifier's inferential role within our theories. If we want to reveal our commitments within formal scientific theory, we can introduce a predicate to be read as 'is physically real' and apply it to anything to which we have thick or thin epistemic access. ${ }^{12}$ Observation is paradigmatically thick access. "Any form of epistemic access which is robust, can be refined, enables us to track the object..., and which (certain) properties of the object itself play a role in how we come to know (possibly other) properties of the object is a thick form of epistemic access" (Azzouni 1997a: 477).

We have thin access to objects to which we lack thick access but to which we could, in principle, have that access. If we have thin access to an object, we can provide an explana-

\footnotetext{
11 See fn 8 .

12 See Azzouni 2004a: 383; and much of Azzouni 2004b, especially Chapter 4.
} 
tion of (or excuse clause for) why we lack thick access to it. For example, we can have thin access to objects outside our light cone, a distant asteroid, say. Despite our lack of access to such an asteroid, we can understand that it can be as real as those in the belt between Mars and Jupiter. Azzouni's defense of eleaticism thus relies on an epistemic argument: we have no reason to believe in causally idle entities because we lack thick or thin access to them. ${ }^{13}$

Colyvan argues that epistemic arguments for an eleatic principle like Azzouni's are unacceptably anthropocentric. ${ }^{14}$ The charge of anthropocentrism against Azzouni is mitigated, to some degree, by his acceptance of thin posits; we need not observe something in order to believe that it exists, but we need to have some (presumably causal) story about why we lack access: it's too small or it's too far away. More recently, Colyvan seems to take Azzouni's epistemic argument to be more promising. "The beauty of Azzouni's thick and thin epistemic access approach is that it does not seem to beg the question against platonism and yet, according to Azzouni, it does rule against ontological commitment to abstract entities such as numbers" (Colyvan 2010: 5).

Colyvan is correct that we want a way to determine whether mathematical objects exist that avoids begging the question. It will not suffice to deny that we should believe that mathematical objects exist because we lack access to them; the question only arises because of our lack of access. To know if we should take our references to mathematical objects seriously, we require some independent criterion for determining our commitments.

In order to take a non-sensible posit as a real thing, Azzouni claims, we need an explanation of our lack of access to it. Such stories rely on our spatial, temporal, or otherwise causal distance from otherwise spatial, temporal, and causally connected objects. Thus, while it may appear that Azzouni's distinctions among posits avoids begging the question against the platonist, they are really just refinements of the underlying reasons for those distinctions: eleaticism. ${ }^{15}$

Like Colyvan's cases, Azzouni's examples are the kinds we are seeking, instances of withholding commitments to objects to which serious theories refer. ${ }^{16}$ Also like Colyvan's examples, these cases are not decisive in favor of an eleatic principle.

It is fairly easy to see how a defender of QI could deny that we should believe in the existence of centers of mass and quasi-particles. They are introduced as idealizing fictions, to make intractable calculations possible. Engineers and experimental physicists require such idealizations. But, says the defender of QI, our best theory is not the one we use for practical purposes. Our best theory will be the one in which we regiment our most sincere, aus-

13 Azzouni actually presents four levels of epistemic access: thick, thin, very thin, and ultra thin. See Azzouni 2004: Chapter 6.

${ }_{14}$ See Colyvan 2001: $\$ 3.2$ and Colyvan 1998: $\$ 3$. See also Colyvan 2010: fn 10, in which he endorses his earlier argument.

15 “Azzouni's main motivation in his earlier articles was the idea that mathematical entities are causally idle and therefore idle simpliciter. As I have already mentioned, I think that this idea is still prominent in his current thinking" (Colyvan 2010: 7). Azzouni denies that he needs to formulate excuse clauses. "[I]t's not my job to give a well-motivated and detailed account of what passes for an excuse. Such excuses issue from science: my job is only to note that fact and indicate its importance..." (Azzouni 2012: 962).

16 Recent work on the status of idealizations in science, including the compelling work of Batterman 2003, further presses the important question of our proper attitude toward such idealizations. 
tere commitments. ${ }^{17}$ The Quinean will accuse any eleatic of intellectual dishonesty: you may not deny that which your theory demands.

This double-talk criticism is essential to QI: if our best theory requires electrons for its bound variables, then we should believe in electrons; if it requires sets, then we are committed to sets. We cannot assert the existence of objects at one moment and then take back those assertions at the next, on pain of inconsistency. ${ }^{18}$

The double-talk criticism appears throughout Quine's work, as in his response to Carnap's internal/external distinction: Once one has accepted mathematical objects as an internal matter, one cannot merely dismiss these commitments as the arbitrary, conventional adoption of mathematical language. Quine's response to the Meinongian Wyman in "On What There Is," is also a double-talk criticism; Quine distinguishes between the meaningfulness of 'Pegasus' and its reference in order to avoid admitting that Pegasus subsists while denying that Pegasus exists. Hilary Putnam, defending Quine's indispensability argument, makes the double-talk criticism explicitly. "It is silly to agree that a reason for believing that $\mathrm{p}$ warrants accepting $\mathrm{p}$ in all scientific circumstances, and then to add 'but even so it is not good enough"' (Putnam 1971: 356).

Worries about double-talk bother Quine's critics as well as his supporters. Field applies the double-talk criticism directly to worries about mathematics. "If one just advocates fictionalism about a portion of mathematics, without showing how that part of mathematics is dispensable in applications, then one is engaging in intellectual doublethink..." (Field 1980: 2).

Like Colyvan's claim that scientific theories invoke non-causal, non-mathematical objects, the double-talk criticism of the eleatic by the indispensabilist is, rightly, a non-question-begging methodological principle. Unfortunately, indispensabilists are liable to commit their own sort of double-talk. If the defender of QI responds to examples like Azzouni's by retreating to an ideal best theory, s/he may also be speaking equivocally: we use centers of mass (quasi-particles, atoms), but we don't really believe that they exist.

This point, that the Quinean appeal to ideal theories masks a kind of double-talk, should not be underestimated. Criteria for theory choice are notoriously complicated. We balance elegance, parsimony, breadth, unification, and simplicity, among other characteristics. There are no precise formulas for how to weigh these complex, interactive factors. We are free to choose among various ways to present a theory: various canonical languages, various mathematical axiomatizations, various formulations of the empirical axioms. For example, Maxwell's equations for electromagnetism can be presented in integral or differential formulations, using a Cartesian basis, vectors, tensors, or even quaternions, ${ }^{19}$ using SI or Gaussian units. The central reason to denigrate a theory which refers to instrumental posits like centers of mass is precisely because we know that they lack causal powers. We see Azzouni's masses and the spring between them and the space in the middle where the center of mass would be located. We say, "There must be a better theory than the one which refers to centers of mass because there is nothing there." It is perilously easy for the

17 Eleatics may welcome talk of ideal theories in attempting to answer the question of which theories to believe fully literally; see e.g. Melia 1995.

18 Not everyone believes that all such double-talk is illicit; e.g. Melia 2000. Insofar as one accepts doubletalk, one rejects QI.

19 See Baker 2001: $\$ 2.3$. 
indispensabilist to anoint as best those theories which avoid quantification over objects, like centers of mass, with no causal powers.

Retreat to an ideal theory thus allows one to import the same kinds of pre-theoretic prejudices against which the Quinean brandishes QI. There are limits to the extent to which the indispensabilist can import such preferences, as QI itself shows. The defender of QI is a reluctant platonist, accepting mathematical objects only because there is no reasonably attractive alternative; most philosophers of mathematics agree that nominalist versions of standard scientific theories are less attractive than their counterparts which contain mathematical axioms. ${ }^{20}$ But the defender of QI who appeals to an ideal theory to reject counter-examples like Azzouni's still engages in a kind of double-talk.

Like Colyvan's examples, the double-talk criticism of eleaticism has the right form: a non-question-begging methodological principle which raises serious worries, even if similar worries apply to the indispensabilist. Perhaps the indispensabilist can argue convincingly that there are non-question-begging reasons to retreat to an ideal theory which quantifies over mathematical objects but not instrumental posits. Still, the invocation of the doubletalk criticism is not categorical and eleatics can defend their double-talk by insisting that their nominalism is principled rather than arbitrary.

Moreover, in $\$ 3$ I put aside Oddie’s worries about specifying the eleatic principle precisely; important distinctions often elude specification. But worries about causation and the compatibility of differing formulations of the eleatic principle cannot be put aside forever.

\section{Beyond the Eleatic and the Indispensabilist}

So despite efforts on both sides, the stalemate between the eleatic and the indispensabilist persists. ${ }^{21}$ Eleatics claim, variously but contentiously, that mathematical terms are meaningless, that mathematical sentences are false or merely vacuously true, or that mathematical objects do not exist. Indispensabilists claim, implausibly, that considerations arising from the construction of empirical theories should compel our belief in abstract objects which have no casual connection to ordinary objects. The eleatic focuses on the causal isolation of mathematical objects. The indispensabilist emphasizes the fact that our best scientific theories refer to mathematical and physical objects indiscriminately, without anointing some references as real and others as merely instrumental. In the remainder of this paper, I'll show how a traditional platonist view, which I call autonomy platonism, embraces important aspects of both positions. ${ }^{22}$

${ }^{20}$ See, for example, the debate between the indispensabilist Colyvan and the easy-road nominalist Melia in Melia 2000, Colyvan 2002, and Melia 2002. While they disagree on much, they agree on the attractiveness of the standard versions of scientific theories which include mathematics.

21 "Perhaps we reach a stand off here. Azzouni takes it that it is possible to get all the benefits of the mathematical explanations I offer from the notation alone. I am inclined to take the scientific explanations in question literally and see them as cases of mathematics (not just mathematical notation) doing the heavy lifting in the cases in question" (Colyvan 2012: 1033).

22 I do not take autonomy platonism to be an entailment of the foregoing arguments of this paper or even from the denials of QI and the eleatic principle. I do take it to be the most plausible account of mathematics. See Marcus 2015 for more details. 
Autonomy platonism consists of an ontological claim and an epistemological claim. The ontological claim, shared with the indispensabilist, is that many mathematical propositions are true and refer to existing mathematical objects. The epistemological claim is that the justification of our mathematical beliefs does not depend on the uses of mathematics in empirical science, contrary to QI. So ' $7+5=12$ ', 'a tangent to a sphere in Euclidean space intersects the radius of that sphere at a right angle', and 'the power set of a set has a cardinality strictly larger than that of the original set' are all true sentences, referring to mathematical objects including numbers, shapes, or sets. They are true regardless of any contingent features of the physical world, no matter what our scientific theories say or how they say it.

There are a variety of forms of autonomy platonism, and so a variety of kinds of independent reasons for believing in the existence of mathematical objects. Some versions invoke a contentious cognitive capacity of mathematical intuition, though it is not an essential component. ${ }^{23}$ Balaguer's plenitudinous platonism (FBP), for example, grounds our knowledge of mathematics in our basic ability to recognize consistency and entailment. On Balaguer's FBP, all consistent mathematical theories truly describe some mathematical domain. We can know about mathematical objects merely because we can recognize the consistency or inconsistency of mathematical theories, without appealing to the applications of mathematics in science or to mathematical intuition. Most philosophers agree that an ability to recognize consistency is not contentious since it is central to any account of our knowledge of logic.

I make two claims here about how autonomy platonism can capture important intuitions supporting both the eleatic and the indispensabilist. First, the eleatic is correct about which existence claims we can infer from scientific theories. Second, the indispensabilist is correct about the existence of mathematical objects. Let's start with the first claim.

An eleatic principle is eminently defensible when applied directly within empirical science. It allows us to rid ourselves of centers of mass and infinitely deep water waves as well as caloric and ghosts, without presuming that there is some idealized version of science that avoids quantifying over them. The eleatic can also explain why the indispensabilist retreats to the promise of an ideal theory in such cases. Given the failure of Colyvan's examples to find non-causal, non-mathematical quantifications within empirical science, there is no reason to reject eleatic principles within science. Even if the indispensabilist rejects the eleatic principle as a categorical criterion for determining what to believe exists, it may remain a useful rule of thumb in determining which scientific theory is best, as we saw in our attitude toward Azzouni's masses on a spring. There is no real disagreement between the eleatic and the indispensabilist in non-mathematical cases; neither believes in centers of mass and such.

The autonomy platonist can emphasize the utility of an eleatic principle within empirical science while limiting its scope to such theories. Such a principle can do its work on centers of mass and ghosts while we refuse to extend it to formal theories like mathematics.

23 Among philosophers who have held some version of autonomy platonism historically are Descartes, Hume, Frege, and Gödel. More recently, Jerrold Katz, John Burgess, Mark Balaguer, and Mark McEvoy have all explored versions of autonomy platonism; see Katz 1998, Burgess 1983, Balaguer 1998 (Chapters 2-4), and McEvoy 2004. Gödel and Katz appeal explicitly to intuition. 
The inference from the effectiveness of an eleatic principle in identifying our commitments in empirical science to the denial of the existence of mathematical objects, one favored by Azzouni, for example, denies the independent legitimacy of mathematics. There is no incompatibility between an eleatic principle, as a criterion for determining the commitments of scientific theory, and mathematical realism, which posits an independent realm of abstract objects. The eleatic principle can tell us how to read the claims of empirical science. We can appeal to independent reasons, like the consistency, stability, and cogency of mathematical theories, to accept mathematical axioms and to believe that mathematical objects exist.

My second claim about the attractiveness of autonomy platonism is that it captures the indispensabilist's claim that mathematical objects exist while denying its implausible allegation that our mathematical beliefs are justified by the same evidence which justifies our empirical beliefs. For the indispensabilist, all posits, mathematical and empirical, are on a par. Even ordinary objects like trees are posits in exactly the same way that sets are. Like logical principles, mathematical beliefs, for the indispensabilist, are connected with our other beliefs in such an integral way that abandoning them in response to a contradiction in our beliefs or theories forces awkward redistributions of truth values among the remaining components. "If asked why he spares mathematics [in revising his theory in the face of recalcitrant experience] the scientist will perhaps say that its laws are necessarily true; but I think we have here an explanation, rather, of mathematical necessity itself. It resides in our unstated policy of shielding mathematics by exercising our freedom to reject other beliefs instead" (Quine 1992: 15).

While it is a simple logical fact that we can hold or cede any claim in a theory by making appropriate adjustments elsewhere, the roles of mathematical objects in our theories are different from the roles of other kinds of posits. We hold mathematical theorems in the background when testing or confirming empirical claims. We do not allow them to be refuted in the ways in which we hold other claims open to disconfirmation. ${ }^{24}$ Mathematical and scientific practice belies the indispensabilist's claims about mathematical justification.

Eleatics and indispensabilists agree that uses of mathematics in scientific theories are indispensable in practice. They disagree about whether those uses are ontologically significant. The autonomy platonist accepts the indispensabilist's claim that they are, while agreeing with the eleatic that the applications of mathematics within empirical theories are not reasons to believe that they are.

The defender of QI looks at a standard scientific theory, with its references to both physical and mathematical objects, and sees no principled way of distinguishing them. Let's imagine that the theory contains Coulomb's law, CL.

$$
\text { CL } \quad \mathrm{F}=\mathrm{k}\left|\mathrm{q}_{1} \mathrm{q}_{2}\right| / \mathrm{r}^{2} \text {, where the electrostatic constant } \mathrm{k} \approx 9 \times 10^{9} \mathrm{Nm}^{2} / \mathrm{c}^{2}
$$

First-order regimentations of CL quantify over both particles (with their charges) and real numbers (the electrostatic constant). The indispensabilist claims that to call the refer-

${ }^{24}$ Elliott Sober has been making this point for over two decades. "If the mathematical statements $M$ are part of every competing hypothesis, then, no matter which hypothesis comes out best in the light of the observations, $M$ will be part of that best hypothesis. $M$ is not tested by this exercise, but is simply a background assumption common to the hypotheses under test" (Sober 1993: 45). See also Sober 1999 and Sober 2005. 
ences to real numbers merely instrumental while accepting the existence of the particles is to make an arbitrary distinction. The truth conditions for the mathematical axioms of our theories are of the same sort as the truth conditions for the other theorems, whether they include mathematical references or not. All theorems will be true if and only if the objects to which they refer exist and have the properties or relations ascribed to them. The autonomy platonist accepts these claims while agreeing with the eleatic that such uses of mathematics are not reasons to believe in mathematical objects.

Mathematical theories are our most secure. Beliefs about mathematics are held more firmly and widely than even our best scientific theories. Where scientific theories are supplanted and abandoned, replaced by better ones, mathematical theories are supplemented and extended. Euclidean geometry persists despite the development of non-Euclidean geometries and its replacement as the framework geometry for our best physics. Proofs first written thousands of years ago remain paradigmatically good mathematics. The core idea of QI is to defend a natural, literal, and sincere reading of our scientific theories with no double-talk. The autonomy platonist extends this natural and literal reading to mathematical theories themselves.

Any version of autonomy platonism thus captures core intuitions of both eleaticism (except for its rejection of mathematical objects) and QI (except for the inference from the applications of mathematical theories to their truth). The autonomy platonist rejects the indispensabilist's claim that our uses of mathematics in science provide reasons to believe in mathematical objects but agrees that our references to mathematical objects within scientific theories are robust. So both the indispensabilist and the autonomy platonist avoid the double-talk of quantifying over mathematical objects while not believing in them. The autonomy platonist cannot be accused, as the eleatic may be, of ostrich nominalism regarding the mathematical elements of our theories.

I believe that autonomy platonism based on either non-empirical (i.e. formal or a priori) evidence or a brute knowledge of consistency is preferable both to nominalism based on an eleatic principle and to platonism based on an indispensability argument. Philosophers who are not independently committed to the non-existence of mathematical objects and who find the relevant motivations for both eleatic and indispensabilist principles compelling might want to adopt this third view. Autonomy platonism will not be palatable to many indispensabilists, who are reluctant to admit any non-empirical evidence, or to many eleatics, who oppose beliefs in any non-causal, non-spatio-temporal objects. So more remains to be said, both in favor of autonomy platonism and against QI and eleaticism. Still, the arguments for autonomy platonism are independent of the central goal of this paper which is to show that recent attempts to break the stalemate between the eleatic and the indispensabilist leave the debate right where it was.

\section{REFERENCES}

Armstrong, David. 1980. The Nature of Mind. Ithaca: Cornell University Press.

Armstrong, David. 1978b. A Theory of Universals: Universals and Scientific Realism, Volume II. Cambridge: Cambridge University Press.

Armstrong, David. 1978a. Nominalism and Realism: Universals and Scientific Realism, Volume I. Cambridge: Cambridge University Press. 
Azzouni, Jody. 2012. “Taking the Easy Road Out of Dodge.” Mind 121: 951-965.

Azzouni, Jody. 2004b. Deflating Existential Consequence: A Case for Nominalism. New York: Oxford University Press.

Azzouni, Jody. 2004a. “Theory, Observation, and Scientific Realism'." British Journal for the Philosophy of Science 55: 371-392.

Azzouni, Jody. 1997a. “Thick Epistemic Access: Distinguishing the Mathematical from the Empirical.” The Journal of Philosophy 94: 472-484.

Azzouni, Jody. 1997b. "Applied Mathematics, Existential Commitment, and the Quine-Putnam Indispensability Thesis." Philosophia Mathematica (3) 5: 193-209.

Baker, Alan. 2001. "Mathematics, Indispensability and Scientific Practice." Erkenntnis 55: 85-116.

Balaguer, Mark. 1998. Platonism and Anti-Platonism in Mathematics. New York: Oxford University Press.

Banks, E.C. 2004. “The Philosophical Roots of Ernst Mach's Economy of Thought.” Synthese 139.1: 23-53.

Batterman, Robert. 2003. The Devil in the Details. Oxford University Press.

Bonjour, Laurence. 1998. In Defense of Pure Reason. Cambridge University Press.

Burgess, John. 1983. "Why I am Not a Nominalist." Notre Dame Journal of Formal Logic 24.1: 93-105.

Burgess, John, and Gideon Rosen. 1997. A Subject with No Object. New York: Oxford.

Cartwright, Nancy. 1983. How the Laws of Physics Lie. Oxford: Clarendon Press.

Colyvan, Mark. 2012. "Road Work Ahead: Heavy Machinery on the Easy Road." Mind 121: 1031-46.

Colyvan, Mark. 2010. “There's No Easy Road to Nominalism.” Mind 119 (474): 285-306.

Colyvan, Mark. 2002. “Mathematics and Aesthetic Considerations in Science.” Mind 111: 69-78.

Colyvan, Mark. 2001. The Indispensability of Mathematics. Oxford University Press.

Colyvan, Mark. 1998. "Can the Eleatic Principle be Justified." Canadian Journal of Philosophy 28.3: 313336.

Field, Hartry. 1989. Realism, Mathematics, and Modality. Oxford: Basil Blackwell.

Field, Hartry. 1980. Science Without Numbers. Princeton: Princeton University Press.

Katz, Jerrold J. 1998. Realistic Rationalism. Cambridge: The MIT Press.

Leng, Mary. 2005. "Mathematical Explanation." In Cellucci, Carlo and Donald Gillies eds, Mathematical Reasoning and Heuristics, King's College Publications, London, 167-189.

Leng, Mary. 2002. "What's Wrong With Indispensability? (Or, The Case for Recreational Mathematics)." Synthese 131: 395-417.

Luce, Duncan, David Krantz, Patrick Suppes, and Amos Tversky. 2007. Foundations of Measurement Volume III: Representation, Axiomatization, and Invariance. Dover.

Maddy, Penelope. 2005. "Three Forms of Naturalism." In Stewart Shapiro, The Oxford Handbook of Philosophy of Mathematics and Logic. Oxford.

Maddy, Penelope. 1992. "Indispensability and Practice." The Journal of Philosophy 89: 275-289.

MacBride, Fraser. 2004. “Can Structuralism Solve the 'Access' Problem?” Analysis 64: 309-318.

Marcus, Russell. 2015. Autonomy Platonism and the Indispensability Argument. Lexington Books.

Marcus, Russell. 2007. “Structuralism, Indispensability, and the Access Problem.” Facta Philosophica 9, 2007: 203-211.

McEvoy, Mark. 2004. “Is Reliabilism Compatible with Mathematical Knowledge?” The Philosophical Forum 35.4: 423-437.

Melia, Joseph. 2002. “Response to Colyvan.” Mind 111:75-79.

Melia, Joseph. 2000. "Weaseling Away the Indispensability Argument.” Mind 109: 455-479.

Melia, Joseph. 1995. "On What There's Not." Analysis 55.4: 223-229.

Oddie, Graham. 1982. "Armstrong on the Eleatic Principle and Abstract Entities." Philosophical Studies 41: 285-95.

Plato. Sophist. Translated by F.M. Cornford. In Hamilton and Cairns, eds., The Collected Dialogues of Plato, Princeton University Press, 1985.

Putnam, Hilary. 1971. Philosophy of Logic. In his Mathematics, Matter, and Method: Philosophical Papers, Vol. I. Cambridge: Cambridge University Press. 
Quine, Willard van Orman. 1992. Pursuit of Truth. Cambridge: Harvard University Press.

Quine, Willard van Orman. 1986. "Reply to Charles Parsons." In Hahn, Lewis Edwin and Paul Arthur Schilpp (eds.). 1986. The Philosophy of W.V. Quine. La Salle: Open Court.

Quine, Willard van Orman. 1978. “Success and the Limits of Mathematization.” In Quine (1981a).

Quine, Willard van Orman. 1960. Word \& Object. Cambridge: The MIT Press.

Quine, Willard van Orman. 1958. "Speaking of Objects." In Ontological Relativity and Other Essays. New York: Columbia University Press.

Quine, Willard van Orman. 1955. "Posits and Reality." In his The Ways of Paradox. Cambridge: Harvard University Press, 1976.

Quine, Willard van Orman. 1951. “Two Dogmas of Empiricism.” In From a Logical Point of View. Cambridge: Harvard University Press, 1980.

Quine, Willard van Orman. 1948. "On What There Is.” In From a Logical Point of View. Cambridge: Harvard University Press, 1980.

Quine, Willard van Orman. 1939. “Designation and Existence.” In Feigl and Sellars, Readings in Philosophical Analysis, Appleton-Century-Crofts, Inc., New York: 1940.

Quine, Willard van Orman. and Nelson Goodman. 1947. “Steps Toward a Constructive Nominalism.” In Goodman, Nelson. Problems and Projects. Indianapolis: The Bobbs-Merrill Company, Inc., 1972.

Sober, Elliott. 2005. "Quine's Two Dogmas." Proceedings of the Aristotelian Society Supplemental Volume 74: 237-280.

Sober, Elliott. 1999. "Testability." Proceedings and Addresses of the American Philosophical Association 73.2: 47-76.

Sober, Elliott. 1993. "Mathematics and Indispensability." The Philosophical Review 102: 35-57.

van Fraassen, Bas. 1980. The Scientific Image. Oxford: Clarendon Press.

Russell Marcus received his Ph.D. from the Graduate School and University Center of the City University of New York and is Assistant Professor of Philosophy at Hamilton College. He works on the philosophy of mathematics and philosophical pedagogy. His monograph, Autonomy Platonism and the Indispensability Argument (Lexington Books) appeared this year.

AddRess: Department of Philosophy, Hamilton College, Clinton NY 13323 USA. E-mail: rmarcus1@hamilton.edu 